\title{
Removal of Low Concentration Phosphate in Phosphogypsum Leachate
}

\author{
Zhixiang Liu, Juan Feng, Chendi Min, Lei Gan and Ying Shi * \\ School of Resources and Safety Engineering, Central South University, Changsha, Hunan, 410083, China
}

\begin{abstract}
In order to find a method for removing low-concentration phosphate from phosphogypsum leachate, modified quartz sand was used as adsorbent. The effects of adsorbent dosage, phosphate concentration and adsorption time on phosphate removal efficiency were investigated. The results show that the optimum dosage of modified quartz sand was $0.024 \mathrm{~g} / \mathrm{mL}$. The effluent phosphate concentration was lower than $0.023 \mathrm{~g} / \mathrm{mL}$, and the phosphate removal efficiency could reach up to $98 \%$.
\end{abstract}

\section{Introduction}

Phosphogypsum (PG) is a solid waste generated in a "wet acid method" process in which phosphate rock is transformed to phosphoric acid. Besides calcium sulphate dihydrate, $\mathrm{PG}$ also contains a large amount of impurities such as soluble phosphate, fluoride and heavy metals ${ }^{[1-2]}$. At present, the reuses of PG only account for $15 \%$ of its yield, and majority is discharged directly on the surface land or into the sea. The soluble phosphate from PG may deposit in nearby soils or migrate to water $^{\mathrm{s}[3-4]}$, therefore Leading to eutrophication ${ }^{[5]}$. As a result, studies are needed to treat the phosphorus content to alleviate environmental pollution related to the $\mathrm{PG}$ storage.

The phosphate concentration of PG leachates could reach up to $5000 \mathrm{mg} / \mathrm{L}$, which are far beyond the limit value of $0.5 \mathrm{mg} / \mathrm{L}$ prescribed by the groundwater environmental standard ${ }^{[6]}$. Several studies tried to treat PG to lower the phosphate concentration in the effluent. Boujelben et al. ${ }^{[7]}$ compared the adsorption of phosphate on aqueous solution by three modified filter materials. The saturated adsorption capacities of the three modified filter materials were found to be $1.5,1.8$, and $0.88 \mathrm{mg} / \mathrm{g}$, respectively. $\mathrm{Lu}$ et $\mathrm{al}^{[8]}$ found that iron oxide coated quartz sands had good adsorption performance for phosphorus in phosphorus wastewater. Yu et al. ${ }^{[9]}$ used chemical flocculation to treat wastewater with a high phosphorus concentration of $1000 \mathrm{mg} / \mathrm{L}$, and the phosphorus removal rate of wastewater could reach $99 \%$. However, most studies focused on wastewater containing high concentrations of phosphate. After the initial treatment of PG with high phosphate concentration, there is still low phosphate concentration left in the effluent. The low concentration of phosphate in phosphogypsum leachate also pose threaten to the surroundings. Therefore, this study aims to offer an approach to adsorption of low concentration of phosphate in phosphogypsum leachate. The modified quartz sand was used as an adsorbent, and the effects of phosphate concentration, adsorption time and adsorbent dosage on the removal efficiency were investigate.

\section{Materials and methods}

\subsection{Preparation of Modified quartz sand}

The quartz sand was supplied by Fengyang County Tengfei Quartz Sand Factory, China. The quartz sand had a whiteness of $86.6 \%$ at $1200^{\circ} \mathrm{C}$, and the particle size distribution was between 14-35 mesh (particle size was between $0.5-1.4 \mathrm{~mm}$ ). The chemical compositions of the quartz sand are shown in Table1.

Table 1. Chemical compositions of quartz sand used in this study.

\begin{tabular}{ccccccccc}
\hline $\begin{array}{c}\text { Chemical } \\
\text { composition }\end{array}$ & $\mathrm{Al}_{2} \mathrm{O}_{3}$ & $\mathrm{SiO}_{2}$ & $\mathrm{Fe}_{2} \mathrm{O}_{3}$ & $\mathrm{CaO}$ & $\mathrm{MgO}$ & $\mathrm{K} 2 \mathrm{O}$ & $\mathrm{Na}_{2} \mathrm{O}$ & $\mathrm{TiO}_{2}$ \\
\hline Content(\%) & 0.23 & 99.10 & 0.047 & 0.030 & 0.011 & 0.017 & 0.008 & 0.06 \\
\hline
\end{tabular}

The quartz sand sample was rinsed repeatedly in deionized water until it was clean. Then, it was baked in a vacuum drying cabinet at $110^{\circ} \mathrm{C}$ for $12 \mathrm{~h}$. After it cooled down, the quartz sand filter medium was soaked in a $1 \mathrm{~mol} / \mathrm{L}$ hydrochloric acid solution for $24 \mathrm{~h}$. Then, the quartz sand was washed again with deionized water until the $\mathrm{pH}$ of the water was neutral. Finally, the quartz sand was dried and used as a pretreated quartz sand filter

\footnotetext{
*shiyingfriend@csu.edu.cn
} 
media. During the drying process, it should be noted that the quartz sand was uniformly stirred to prevent the quartz sand from overheating and blackening.

The heating evaporation method was applied to the surface-pretreated quartz sand for modified coating treatment. $500 \mathrm{~g}$ of cleaned quartz was mixed with $150 \mathrm{~mL}$ of $2.5 \mathrm{~mol} / \mathrm{L} \mathrm{FeCl}_{3}$ solution, then dried at $110^{\circ} \mathrm{C}$ and heated in a muffle furnace at $600^{\circ} \mathrm{C}$ for $3 \mathrm{~h}$. Then, $75 \mathrm{~mL}$ of $2.5 \mathrm{~mol} / \mathrm{L} \mathrm{FeCl}_{3}$ solution was added to $150 \mathrm{~g}$ of the pretreated quartz sand. Then, it was heated at $110^{\circ} \mathrm{C}$ for $3 \mathrm{~h}$ and placed in the air for $21 \mathrm{~h}$. This process was recycled for 2-3 times to ensure stable coating. Finally, it was washed with a $0.1 \mathrm{~mol} / \mathrm{L} \mathrm{NaOH}$ solution, rinsed with deionized water, and dried at $110^{\circ} \mathrm{C}$. After it cooled down, modified quartz sand filter material was obtained.

\subsection{Preparation of PG Leachate with Low Concentration phosphate}

The PG was leached with deionized water at a liquid to solid ratio of $5: 1$ for $24 \mathrm{~h}$ at $25^{\circ} \mathrm{C}$. A leachate with a phosphate concentration of $985 \mathrm{mg} / \mathrm{L}$ was obtained after standing for $30 \mathrm{~min}$. Then, the leachate was diluted to the experimental solutions with phosphate concentrations of $0.51,1.30,1.40,1.85,4.38 \mathrm{mg} / \mathrm{L}$, respectively.

\subsection{Experiment design}

$50 \mathrm{~mL}$ of leachate with different phosphorus concentration $(0.51,1.30,1.40,1.85,4.38 \mathrm{mg} / \mathrm{L})$ and modified quartz sand (the dosages of $0.2,0.6,1.2$, and $2.0 \mathrm{~g}$, respectively) were mixed in a baker using a magnetic stirrer at the speed of $150 \mathrm{r} / \mathrm{min}$. The liquid sample was obtained at mixing times of $1,4,8,12$ and $24 \mathrm{~h}$, and then they were filtered through qualitative filter papers. Then, the leachates were filtered using $0.45 \mu \mathrm{m}$ filters. Finally, the phosphate concentration in leachate was determined using an ammonium molybdate tetrahydrate spectrophotometry method ${ }^{[10]}$. Each test was triplicated, and the average value was used for date process.

\section{Results and discussion}

\subsection{Effect of dosage of modified quartz sand on phosphate removal}

The relation between phosphate removal rate and the dosage of modified quartz sand is presented in Fig. 1. It can be seen that the adsorbent dosage was a significant factor controlling the phosphate removal efficiency. As shown in Fig. 1, when the initial phosphate concentration was $1.30 \mathrm{mg} / \mathrm{L}$, the phosphate removal rate increased from $31.54 \%$ to $98.77 \%$ with the increase in the adsorbent dosage from $0.2 \mathrm{~g}$ to $2.0 \mathrm{~g}$. The phosphate removal is likely attributed to effective adsorption by the modified quartz sand ${ }^{[11]}$. With the increase in the adsorbent dosage, the total effective adsorption area and the effective activated sorption sites increased, and as the result, more phosphate was adsorbed. However, when the dosage of modified quartz sand increased to a certain extent, almost all of the phosphate was adsorbed by the adsorbent. Then, the increase in the dosage of modified quartz sand had a slight influence on the phosphate removal efficiency.

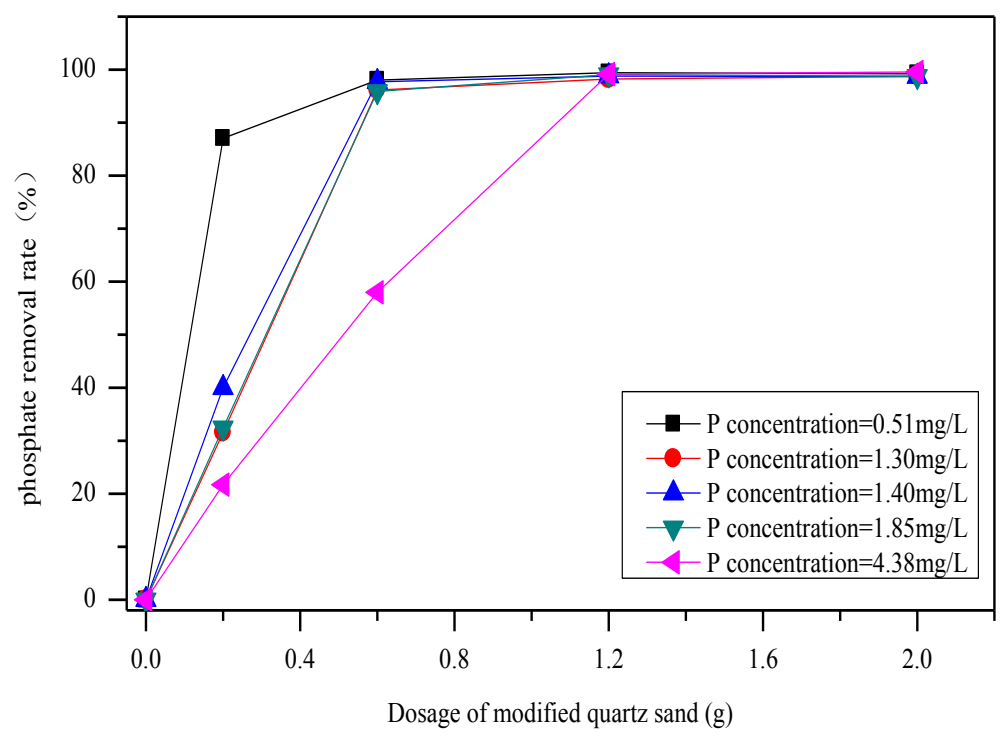

Figure 1. The phosphate removal efficiency with different dosage of modified quartz sand.

As shown in Fig. 1, with the modified quartz sand weight of $0.2 \mathrm{~g}$, the phosphate removal rate of the leachate with a concentration between $1.00 \mathrm{mg} / \mathrm{L}$ and $5.00 \mathrm{mg} / \mathrm{L}$ was less than $50 \%$. However, as the amount of modified quartz sand increased to $1.2 \mathrm{~g}$, the phosphate removal rates of leachates were all over $98 \%$. At the same time, the effluent phosphorus content was much lower than the limit concentration of $0.5 \mathrm{mg} / \mathrm{L}^{[12]}$. This indicated that the optimum amount of modified quartz sand was about $0.024 \mathrm{~g} / \mathrm{ml}$ when the phosphate concentration was less than $5 \mathrm{mg} / \mathrm{L}$. 


\subsection{Effect of phosphate concentration on phosphate removal}

Fig. 2 shows that the phosphate removal rate decreased greatly from $87.06 \%$ to $21.69 \%$ with the increase of the phosphate concentration from $0.51 \mathrm{mg} / \mathrm{L}$ to $4.38 \mathrm{mg} / \mathrm{L}$. The low phosphorus removal rate of the leachate might be mainly due to the fact that the maximum adsorption amount of the modified quartz sand was not reached. As shown in Fig. 2, The amount of phosphate adsorbed increases as the phosphate concentration increases. The adsorption of phosphate via modified quartz sand increased rapidly from $0.111 \mathrm{mg} / \mathrm{g}$ to $0.238 \mathrm{mg} / \mathrm{g}$ when the phosphate concentration increased from $0.51 \mathrm{mg} / \mathrm{L}$ to $4.38 \mathrm{mg} / \mathrm{L}$. This could be explained by the fact that high concentrations of phosphate could produce sufficient mass transfer driving force, and therefore promoting the adsorption of phosphate by the modified quartz sand. Therefore, the increase in phosphate concentration could significantly rise the utilization of the adsorbent before the modified quartz sand reached the saturated adsorption capacity.

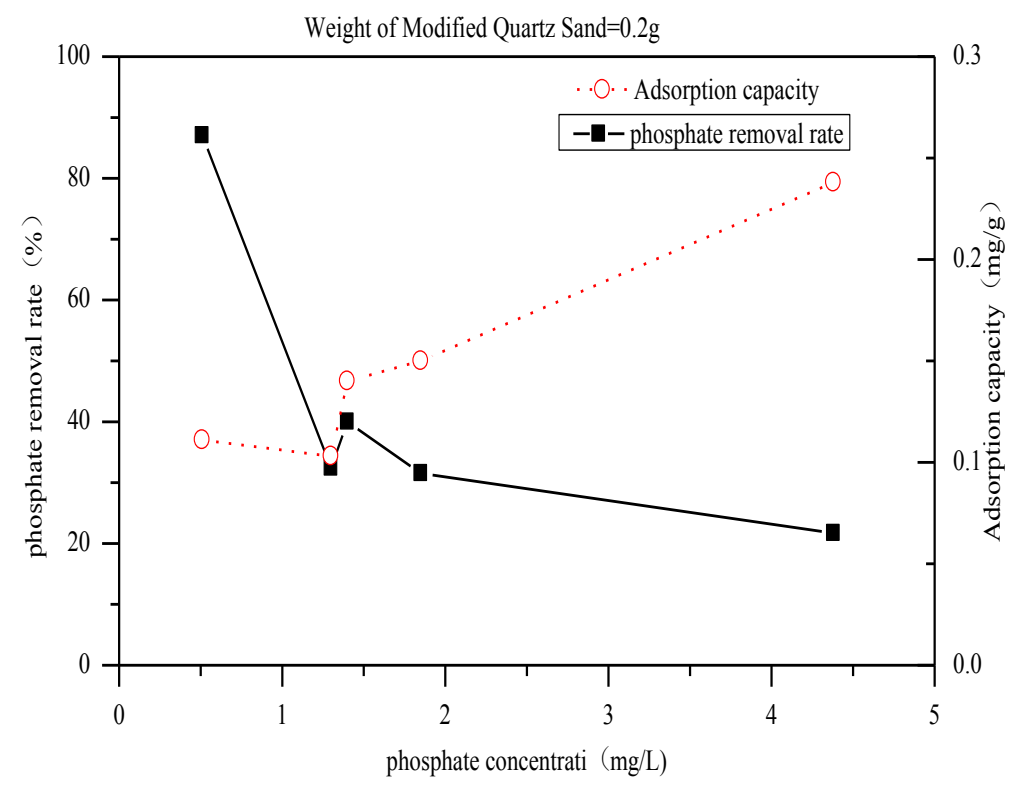

Figure 2. Effect of phosphate concentration on phosphate removal efficiency.

\subsection{Effect of adsorption time on phosphate removal rate}

The adsorption of phosphate by modified quartz sand was a dynamic reversible process. Adequate contact time between the adsorbent and the adsorbate was required to complete the adsorption. Therefore, adsorption time was one of the most important factors to measure the phosphate removal efficiency. The development of phosphate removal rate in the function of adsorption time is present in Fig. 3.

As shown in Fig. 3a, the adsorption effect of the modified filter material could be effectively increased by prolonging the adsorption time. When the adsorption time increased from $1 \mathrm{~h}$ to $24 \mathrm{~h}$, the phosphate removal rate of the leachate with the phosphate concentration of $4.38,1.85,1.40,1.30$ and $0.51 \mathrm{mg} / \mathrm{L}$ increased from $7.53 \%, 10.81 \%, 19.29 \%, 1.24 \%, 29.22 \%$ to $21.69 \%$, $32.43 \%, 40 \%, 31.54 \%$ and $87.06 \%$, respectively. It may be attributed to the fact that as the adsorption time increased, the active center of the surface of the modified quartz sand was gradually covered, and the adsorption of phosphate gradually increased, therefore increasing the phosphate removal rate. However, with the saturation of the adsorption capacity of the modified quartz sand, the removal rate tended to be stable. 

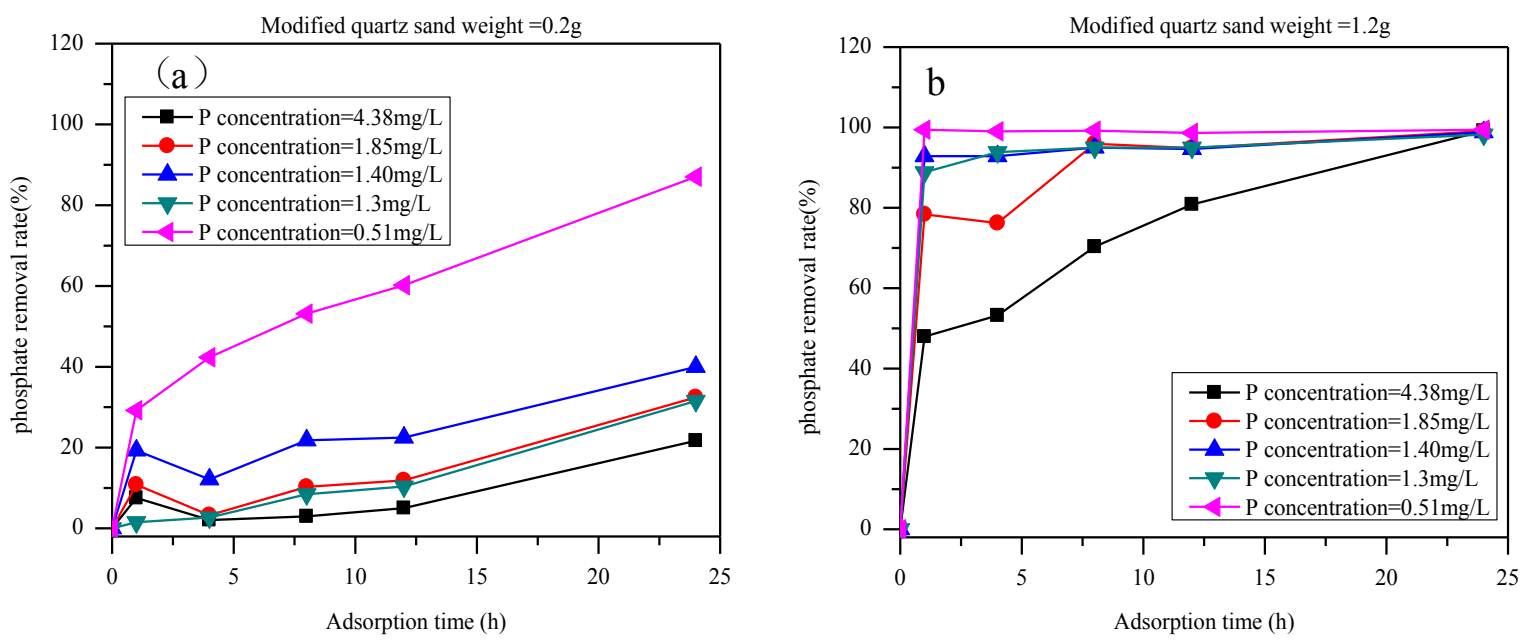

Figure 3. Phosphate removal rate with different modified quartz sand dosages (a:0.2g; b:1.2g).

The adsorption time for achieving the best phosphate removal efficiency was closely related to the modified quartz sand dosage. As shown in Fig. 3, when the modified quartz sand weight was $0.2 \mathrm{~g}$, the phosphate removal rate of leachate increased continuously within $24 \mathrm{~h}$. However, after the amount of modified quartz sand increased to $1.2 \mathrm{~g}$, except for the phosphate concentration of 4.38 and $1.85 \mathrm{mg} / \mathrm{L}$, the phosphate removal rates of leachate were all stable at $1 \mathrm{~h}$. Compared to the effect of amount modified quartz sand added into phosphogypsum leachate, the effect of adsorption time was not very significant. Therefore, as the amount of modified quartz sand increased, the adsorption time could reduce correspondingly to save the adsorption cost.

\section{Conclusion}

(1) The optimum modified quartz sand content of low concentration leachate with a phosphate concentration range of $0.5-5.0 \mathrm{mg} / \mathrm{L}$ is about $0.024 \mathrm{~g} / \mathrm{mL}$.

(2) Compared to the effect of modified quartz sand on the phosphate removal rate of phosphogypsum leachate, the effect of adsorption time was not so significant.

\section{Acknowledgements}

This work was sponsored by The National Natural Science Foundation of China (51974359 and 51674288).

\section{References}

1. Rutherford, P.M., Dudas, M.J., Samek, R.A. (1994) Environmental impacts of phosphogypsum. Science of the Total Environment, 149: 1-38.

2. Gan, L., LI X.B., Fan, Y., et al. (2017) Study on environmental influence of PG cemented backfilling and utilization of full phosphorus slag. Science \& Technology Review, 13: 86-91.
3. Rashad, A.M. (2017) Phosphogypsum as a construction material. Journal of Cleaner Production, 166: 732-743.

4. Jiang, L.G., Liang, B., Xue, Q., et al. (2016) Characterization of phosphorus leaching from phosphate waste rock in the Xiangxi River watershed, Three Gorges Reservoir, China. Chemosphere, 150: 130-138.

5. Jiang, X.P. (2016) The hazards and prevention of eutrophication in water bodies. China Venture Capital, 18: 348 .

6. Li, X.B., Du, J., Gao, L., et al. (2016) Immobilization of phosphogypsum for cemented paste backfill and its environmental effect. Journal of Cleaner Production, 156: 137-146.

7. Boujelben, N., Bouzid, J., Elouear, Z., et al. (2008) Phosphorus removal from aqueous solution using iron coated natural and engineered sorbents. Journal of Hazardous Materials, 151: 103-110.

8. Copetti, D., Finsterle, K., Marziali, L., et al. (2016) Eutrophication management in surface waters using lanthanum modified bentonite: A review. Water Research, 97: 162-174.

9. Yu, H.M., Wang, C., Ling, w., et al. (2019) Treatment of high concentration phosphorus wastewater in seafood processing using chemical flocculation. Journal of Water Resources and Water Engineering, 30: 24-29.

10. The State Environmental Protection Administration The Water and Wastewater Monitoring Analysis Method Editorial Board. (2002) Water and Wastewater monitoring analysis method. China Environmental Science Press, Beijing.

11. Feng, C.M, Long, Y.J., Li, G.B. (2007) Performance of absorption and filtration of iron oxide coated-sand for phosphorus removal. Technology of water treatment, 12: 70-72. 
12. Standardization Administration of the People's Republic of China. (1996) Integrated wastewater discharge standard, GB 8978-1996. Standards Press of China, Beijing. 